\title{
Inertia Modeling of Brushless Doubly-fed Induction Generator and Stability Analysis of Wind Power Grid
}

\author{
Min LU* \\ College of Mechanical and Electronic Engineering \\ Shihezi University \\ Shihezi, Xinjiang, China \\ E-mail: lm_shz@163.com \\ +* Corresponding author
}

\author{
Hui LI \\ College of Mechanical and Electronic Engineering \\ Shihezi University \\ Shihezi, Xinjiang, China \\ E-mail: cqulh@163.com
}

\author{
Mi ZHAO \\ College of Mechanical and Electronic Engineering \\ Shihezi University \\ Shihezi, Xinjiang, China \\ E-mail: Zhaomi530@163.com
}

\begin{abstract}
Brushless doubly-fed induction generator (BDFIG) leave out the slip ring and brush as the dual-stator structure, which can improve the reliability, reduce maintenance costs and expect to be widely used in wind power system. The current converter is installed in the one of the dual stator winding: control winding $(\mathrm{CW})$, then the motor rotor is linked together with the wind turbines. The mechanical and electric inertia have different with the doubly-fed induction generator (DFIG) because of the special structure and these features directly affect the stability of power system. On the establishment and qualitative analysis of the inertia models of single and group motors of BDFIG, the vector control (VC) of the small signal model is established to solve the eigenvalue for quantitative analysis of the stability of the wind power system connected to the grid, and compared with squirrel-cage asynchronous induction generator (SCAIG), DFIG and permanent magnet synchronous generator (PMSG) to analyze the different effects on the stability of the power system. The simulation results prove the correctness of the model.
\end{abstract}

Keywords-brushless doubly-fed induction generator (BDFIG); dual-stator structure; inertia model; system equivalent inertia; stability of power system

\section{INTRODUCTION}

Doubly-fed induction generator (DFIG) has become the main types of large wind farms, however, the power electronic converters make the decoupling relationship between the speed of wind turbine and power grid frequency. Its rotational kinetic energy was "hidden" and almost no contribution to the moment of inertia of the power system [1-2].The stator of BDFIG is made with the power winding
(PW) and control winding (CW), there no direct magnetic coupling between the two windings and through the special design the rotor can be magnetic coupled respectively with the PW and CW. Hence even absence of brush and slip ring, the machine still can realize control [3-4]. The difference in the structure, and have different influence on power system; the inertia analysis is different with DFIG and needs to analysis separately.

\section{The Model of THE System Equivalent INERTIA OF BDFIG}

\section{A. The Electromagnetic Relation Model of BDFIG}

The motor of the electromagnetic torque expression is:

$$
T_{e}=p_{p} L_{p r}\left(i_{p q} i_{r d}-i_{p d} i_{r q}\right)+p_{c} L_{c r}\left(i_{c q} i_{r d}+i_{c d} i_{r q}\right)
$$

The equation of motion is:

$$
\left(J_{p}+J_{c}\right) \frac{d \omega_{r}}{d t}=T_{e}-\left(F_{p}+F_{c}\right) \omega_{r}-T_{L}
$$

\section{B. The Model of Single Machine Inertia of BDFIG}

According to the former section can find that the inertia of the BDFIG is the sum of the power and control sub-motor, and no hidden kinetic energy due to the motor rotor directly connected with the draft, according to the kinetic energy formula available:

$$
E_{\mathrm{k}}=\int\left(P_{m}-P_{e}\right) d t=\int\left(J_{p}+J_{c}\right) \omega_{m} d \omega_{m}=\frac{1}{2}\left(J_{p}+J_{c}\right) \omega_{m}^{2}=\frac{\left(J_{p}+J_{c}\right) \omega_{e}^{2}}{2\left(P_{p}+P_{c}\right)^{2}}
$$


Where $\omega_{m}, \omega_{e}$ are the mechanical angular velocity and synchronous electrical angular velocity of motor respectively, $J$ and $p$ are the rotational inertia of the motor and the pole pair numbers, subscribe 1 and 2 are indicate power side and control side.

A single BDFIG inertia time constant is defined as:

$$
H=\left(J_{p}+J_{c}\right) \omega_{e}^{2} / S_{N}
$$

Then, The inertial time constant for the power system contain the wind BDFIG is:

$$
H_{t o t}=\left[\sum_{i=1}^{n}\left(\frac{1}{2 p_{i}^{2}} J_{i} \omega_{e}^{2}\right)+\sum_{j=1}^{m} E_{k_{-} B D F I G, j}\right] / S_{N_{-} t o t}
$$

Where $\mathrm{n}, \mathrm{m}$ are the number of synchronous generator and BDFIG, $\mathrm{J}_{\mathrm{i}}$ and $\mathrm{p}_{\mathrm{i}}$ are the rotational inertia of the synchronous generator and pole pairs number respectively, is the total rated capacity, is The rotational kinetic energy of the unit $j$ of BDFIG

Through the equation (5) can analyze the inertial time constant of BDFIG is larger than the single conventional asynchronous generator.

Inertia $\mathrm{M}$, also known as the machine start time $\mathrm{TM}$, defined as rated torque to the rotor speed from 0 to the time required to rated speed, generally, $\mathrm{M}=2 \mathrm{H}$.

The relationship between the single machine inertia and the system inertia is:

$$
M_{M}=\frac{1}{P_{M}} \sum_{j=1}^{n} M_{j} P_{j}
$$

Where $\mathrm{M}_{\mathrm{j}}, \mathrm{M}_{\mathrm{M}}$ are one unit and the system equivalent inertia respectively, $\mathrm{P}_{\mathrm{j}}, \mathrm{P}_{\mathrm{m}}$ are the generating capacity of each unit and the equivalent system.

\section{The Model and Analysis of the System EQUIVALENT INERTIA}

A. The Effect on the System Equivalent Inertia by the Single Machine Inertia

Split(6) into the model of system equivalent inertia, then

$$
M^{\prime}=\frac{1}{P_{1}+\Delta P}\left(M_{1} P_{1}+M_{B D F M} \Delta P\right)
$$

Where is the system equivalent inertia is after access to the wind power, $\mathrm{M}_{1}$ is the original system equivalent inertia, $\mathrm{P}_{1}$ is the original system output, $\Delta P$ is the capacity of wind power, $\mathrm{M}_{\mathrm{BDFM}}$ is the inertia of BDFIG.

Considering (7) can derive that if $\Delta P$ and $P_{1}$ are same orders of magnitude, then the system equivalent inertia is increase and the system stability is improved after access to the wind power.
B. A Single Unit Output Effect the Equivalent Moment of Inertia of the System

When the wind power output of generating is changed, the system equivalent inertia is:

$$
M^{\prime}=\frac{M_{1} P_{1}+M_{B D F I G} \Delta P_{1}}{P_{1}+\Delta P_{1}}=M_{1}-\frac{\Delta P_{1}\left(M_{1}-M_{\text {BDFIG }}\right)}{P_{1}+\Delta P_{1}}
$$

Where $\Delta P_{1}$ is the increased output of wind turbines.

Considering (8) can derive that the output of BDFIG is increased, the system equivalent inertia is also increased, and also enhance the stability of the system.

\section{The Small Signal Model of Flux Oriented VECTOR CONTROL OF BDFIG}

Due to the grid power winding is connected to a power grid and can be taken for the grid voltage does not change. So can get $\Delta V_{p d}=0, \Delta V_{p d}=0$, meanwhile the voltage of rotor is zero, means $\Delta V_{d r}=0, \Delta V_{q r}=0$.

Different working mode and control mode can form different small signal models. This paper studies the generator model of PW flux vector orientation, means, control block diagram see literature [7].The inputs of control system are drag torque and rotational speed, the state variables are $\left(i_{p d}, i_{p q}, i_{c d}^{\prime}, i_{c q}^{\prime}, i_{r d}^{\prime}, i_{r q}^{\prime}, u_{c d}^{\prime}, u_{c q}^{\prime}, \omega_{r}, \theta_{r}\right)^{T}$, the control winding voltage is:

$$
\left\{\begin{array}{l}
u_{c d}^{\prime}=\frac{r_{c}^{\prime}\left(L_{c}^{\prime} L_{r}^{\prime} \sigma_{p}-L_{c r}^{\prime 2}\right)}{r_{r}^{\prime} L_{r}^{\prime} \sigma_{p}}\left(i_{c d r e f}^{\prime}-i_{c d}^{\prime}\right)+r_{c}^{\prime} \int\left(i_{c d r e f}^{\prime}-i_{c d}^{\prime}\right) d t+D_{c d}^{\prime} \\
u_{c q}^{\prime}=\frac{r_{c}^{\prime}\left(L_{c}^{\prime} L_{r}^{\prime} \sigma_{p}-L_{c r}^{\prime 2}\right)}{r_{r}^{\prime} L_{r}^{\prime} \sigma_{p}}\left(i_{c q r e f}^{\prime}-i_{c q}^{\prime}\right)+r_{c}^{\prime} \int\left(i_{c q r e f}^{\prime}-i_{c q}^{\prime}\right) d t+D_{c q}^{\prime}
\end{array}\right.
$$

Where $D_{c d}^{\prime} D_{c q}^{\prime}$ are disturbers terms of PI regulators, it can be ignorant if the PI parameters set reasonably. Then can get:

$$
\left\{\begin{array}{l}
\rho \Delta u_{c d}^{\prime}=\frac{r_{c}^{\prime}\left(L_{c}^{\prime} L_{r}^{\prime} \sigma_{p}-L_{c r}^{\prime 2}\right)}{r_{r}^{\prime} L_{r}^{\prime} \sigma_{p}}\left(\rho \Delta i_{c d r e f}^{\prime}-\rho \Delta i_{c d}^{\prime}\right)+r_{c}^{\prime}\left(\Delta i_{c d r e f}^{\prime}-\Delta i_{c d}^{\prime}\right) \\
\rho \Delta u_{c q}^{\prime}=\frac{r_{c}^{\prime}\left(L_{c}^{\prime} L_{r}^{\prime} \sigma_{p}-L_{c r}^{\prime 2}\right)}{r_{r}^{\prime} L_{r}^{\prime} \sigma_{p}}\left(\rho \Delta i_{c q r e f}^{\prime}-\rho \Delta i_{c q}^{\prime}\right)+r_{c}^{\prime}\left(\Delta i_{c q r e f}^{\prime}-\Delta i_{c q}^{\prime}\right)
\end{array}\right.
$$

Meanwhile:

$$
\begin{aligned}
& \rho \Delta i_{c \text { cref }}^{\prime} \approx-i_{c q 0 r e f}^{\prime}\left(P_{p}+P_{c}\right) \Delta \omega_{r}, \rho \Delta i_{c \text { cree }}^{\prime} \approx-i_{c d 0 r e f}^{\prime}\left(P_{p}+P_{c}\right) \Delta \omega_{r}, \\
& \rho \Delta i_{c d}^{\prime} \approx-i_{c q 0}^{\prime}\left(P_{p}+P_{c}\right) \Delta \omega_{r}, \rho \Delta i_{c q}^{\prime} \approx i_{c d 0}^{\prime}\left(P_{p}+P_{c}\right) \Delta \omega_{r}, \\
& \Delta i_{c \text { cref }}^{\prime} \approx-i_{c q u r e f}^{\prime}\left(P_{p}+P_{c}\right) \Delta \theta_{r}, \Delta i_{c q r e f}^{\prime} \approx-i_{c d 0 r e f}^{\prime}\left(P_{p}+P_{c}\right) \Delta \theta_{r}, \\
& \Delta_{c d}^{\prime} \approx-i_{c q 0}^{\prime}\left(P_{p}+P_{c}\right) \Delta \theta_{r}, \quad \Delta i_{c q}^{\prime} \approx i_{c d 0}^{\prime}\left(P_{p}+P_{c}\right) \Delta \theta_{r},
\end{aligned}
$$


Split into(10):

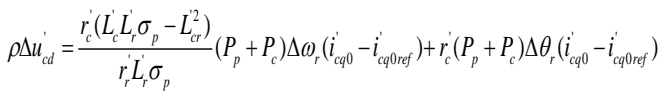

$$
\begin{aligned}
& \rho \Delta u_{c q}^{\prime}=-\frac{r_{c}^{\prime}\left(L_{c}^{\prime} L_{r}^{\prime} \sigma_{p}-L_{c}^{2}\right)}{r_{r}^{\prime} L_{r}^{\prime} \sigma_{p}}\left(P_{p}+P_{c}\right) \Delta \omega_{r}\left(i_{c d 0}^{\prime}+i_{c d 0 r e f}^{\prime}\right)-r_{c}^{\prime}\left(P_{p}+P_{c}\right) \Delta \theta_{r}\left(i_{c d 0}^{\prime}-i_{c d 0 r f}^{\prime}\right)
\end{aligned}
$$

The linearized model can get small signal model of the PW flux orientation, the state variables are $\left[\Delta i_{p d}, \Delta i_{p q}, \Delta i_{c d}^{\prime}, \Delta i_{c q}^{\prime}, \Delta i_{r d}^{\prime}, \Delta i_{r q}^{\prime}, \Delta u_{c d}^{\prime}, \Delta u_{c q}^{\prime}, \Delta \omega_{r}, \Delta \theta_{r}\right]^{T}, \quad$ input variables are $\left(0,0,0,0,0,0,0,0,0, T_{L}\right)^{T}$, the standard form is:

$$
\Delta \dot{x}=A \Delta x+B \Delta u
$$

\section{The Analysis of Small Signal Stability and DisCUSSION OF THE RESULTS OF SIMULATION}

According to the small signal model, the stable operation condition can obtain by lyapunov stability criterion. According to the linear system theory and lyapunov stability criterion, the system is asymptotically stable as long as the pole of linear time-invariant matrix A has the negative real component and then judges the lyapunov stability of linear time-varying systems under periodic changes [8-9].

\section{A. The Simulation Results}

This paper adopts the model of Hexi power grid in the literature [10] .

1) The process simulation and calculation

a) The analysis of influence of the different type for wind turbine

Literature [10] calculated and analyzed the influence of on the power grid after access the wind power of squirrelcage asynchronous induction generator (SCAIG), doubly-fed induction generator (DFIG) and permanent magnet synchronous generator (PMSG), according to the analysis calculate the small disturbance of BDFIG based on the simulation conditions:
TABLE I. THE EIGENVALUE OF DifFERENT WIND POWER OUTPUT OF

\begin{tabular}{|c|c|c|c|c|c|}
\hline $\begin{array}{l}\text { Type of } \\
\text { generator }\end{array}$ & Mode & Real part & $\begin{array}{c}\text { Imaginary } \\
\text { part }\end{array}$ & Frequency & $\begin{array}{c}\text { Damping } \\
\text { ratio }\end{array}$ \\
\hline \multirow{4}{*}{ SCAIG } & 1 & -0.38046 & 6.67564 & 1.063 & 5.69 \\
\hline & 2 & -0.00712 & 10.52448 & 1.6751 & 0.0677 \\
\hline & 3 & -0.29746 & 3.53303 & 0.56223 & 8.3899 \\
\hline & 4 & -0.03897 & 3.01024 & 0.47933 & 1.2946 \\
\hline \multirow{3}{*}{ DFIG } & 1 & -0.35699 & 6.6882 & 1.065 & 5.33 \\
\hline & 2 & -0.00677 & 10.21756 & 1.627 & 0.0663 \\
\hline & 3 & -0.28836 & 3.536865 & 0.56195 & 8.1259 \\
\hline \multirow{5}{*}{ PMSG } & 4 & -0.02149 & 2.89808 & 0.46167 & 0.7414 \\
\hline & 1 & -0.3553 & 6.70704 & 1.068 & 5.29 \\
\hline & 2 & -0.006744 & 10.24896 & 1.632 & 0.0658 \\
\hline & 3 & -0.292062 & 3.58588 & 0.571 & 8.1179 \\
\hline & 4 & -0.00609 & 2.86315 & 0.45591 & -0.2126 \\
\hline \multirow{4}{*}{ BDFIG } & 1 & -0.41236 & 6.64758 & 1.060 & 5.90 \\
\hline & 2 & -0.00724 & 10.76382 & 1.7234 & 0.0732 \\
\hline & 3 & -0.34251 & 4.78473 & 0.58932 & 8.4675 \\
\hline & 4 & -0.18294 & 3.56274 & 0.87294 & 3.8927 \\
\hline
\end{tabular}
CORRESPONDING OSCILLATION MODEL

From the calculation results can be seen that the system equivalent inertia of BDFIG is the biggest and best damping characteristics, the second is SCAIG, then is DFIG, and the system equivalent inertia of PMSG is the minimum, the small signal stability of power grid is the worst. The results also verified the relationship between the system equivalent inertia and the system damping ratio is correct, the smaller the system equivalent inertia, the worse the small signal stability.

2) The impact analysis of wind farm output of power grids

a) The simulation conditions

This paper selects the small load operation mode winter in 2012, then calculates and analyze of the relationship between the wind power output of $0,20 \%, 40 \%$ and $60 \%$ with the system inertia and small perturbation. Set four kinds of wind power output can obtain: 
TABLE II. The EIgENVALUE OF DifFERENT Wind POWER OUTPUT OF CORRESPONDING OSCILLATION MODEL

\begin{tabular}{|c|c|c|c|c|c|}
\hline Output ratio & Mode & Real part & Imaginary part & Frequency & Damping ratio \\
\hline \multirow{4}{*}{$0 \%$} & 1 & 3.6462E-002 & 4.279005 & 0.681025 & 0.8521 \\
\hline & 2 & -0.729679 & 8.894783 & 1.415649 & 8.176 \\
\hline & 3 & -0.730932 & 10.763464 & 1.713059 & 6.7753 \\
\hline & 4 & $-6.84 \mathrm{E}-004$ & 13.85734 & 2.20546 & 0.0049 \\
\hline \multirow{4}{*}{$20 \%$} & 1 & 0.000023 & 4.276451 & 0.67384 & 0.7632 \\
\hline & 2 & -0.00015 & 8.97463 & 1.47873 & 8.02634 \\
\hline & 3 & -0.00026 & 10.87463 & 1.73625 & 6.65743 \\
\hline & 4 & -0.00037 & 13.80294 & 2.19723 & 0.00382 \\
\hline \multirow{4}{*}{$40 \%$} & 1 & 0.000567 & 4.76453 & 0.69362 & 7.8735 \\
\hline & 2 & -0.00034 & 8.84373 & 1.48372 & 6.2636 \\
\hline & 3 & -0.00037 & 10.54637 & 1.73272 & 0.00278 \\
\hline & 4 & -0.00049 & 13.67257 & 2.16327 & 0.0020 \\
\hline \multirow{4}{*}{$60 \%$} & 1 & 0.006183 & 4.264271 & 0.67902 & -0.145 \\
\hline & 2 & -0.67261 & 8.893912 & 1.41623 & 7.541 \\
\hline & 3 & -0.6526 & 10.85413 & 1.72837 & 6.0016 \\
\hline & 4 & -0.00111 & 13.89463 & 2.21521 & 0.0018 \\
\hline
\end{tabular}

From the results can see that the damping ratio continues to decrease when wind power output increases, means that the large-scale wind power access the grid intensively, due to the small inertia of wind power, the system equivalent inertia is relatively weak with the increase of wind power output.

\section{CONCLUSION}

- The special physical structure of BDFIG improves the inertia characteristics of wind turbine, which makes the BDFIG has a certain supporting function to the stability of the power grid, and verify the conclusions by compared with the SCAIG, the DFIG, the PMSG;

- Through the eigenvalue by the small signal model of the quantitative calculation and comparison with the SCAIG, the DFIG concluded that different wind turbine had the different affections on the small disturbance stability of power grids, and is verified the different effect on the stability of the power grid when the mass concentration of different output.

Considering the limitations of present study condition, there has been no prototype experiments, in the future work is proposed to do experiments on the above conclusion, further in-depth study the inertia characteristic of BDFIG and the grid frequency stability mechanism and improvement measures.

\section{ACKNOWLEDGMENTS}

This work was supported by the Natural Science Foundation of China (51467018).

\section{REFERENCES}

[1] LI Hui, ZHANG Zhike, YANG Chao, ZHAO Bin, TANG Xianhu. Analysis of parameter and operation state on small-signal stability of doubly-fed wind turbine generation system,Electric Machines and Control, vol. 17, no.22,(2013),pp:14-21

[2] LI Hui, CHEN Yaojun, LI Yang, LIU Shengquan, YANG Dong, LIANG Yuanyuan, LANYongsen. Impact of DFIG-based wind farms interconnected to power grid on subsynchronous oscillation of turbo generator. Electric Machines and Control,vol.19,no.6,(2015),pp:47-54

[3] Tohidi, S, Zolghadri, M,R; Oraee, H; Oraee,A, Dynamic modeling of a wind turbine with brushless doubly fed induction generator,2012 Power Electronic \& Drive System \& Technologies Conference, Tehran, Iran,(2012) February 15-16,pp:490-494

[4] Pablo E.Troncoso, Pedro E.Battaiotto and Ricardo J.Mantz, Acticive and Reactive Power Control Capability in Wind Generation based on BDFIG machine,2015 IEEE PES Innovative Smart Grid Technologies Latin America, Montevideo, Uruguay,(2015),October 5-7,pp:546-551

[5] Guan hongliang, The Study of the Influence of the Large-scale Wind Power Generation on the Small Disturbance Stability of Power System, PhD thesis, Hebei:North China Electric Power University(Baoding), 2008

[6] HAN Li, LUO Jie, LI Jingcan, PAN Hongguang, Stability analysis and its influence factors study of brushless doubly-fed machine, Electric Machines and Control,vol.17,no.7,(2013),pp:105-112

[7] Shiyi Shao, Ehsan Abdi, Farhad Barati, and Richard McMahon,Stator-Flux-Oriented Vector Control for Brushless Doubly Fed Induction Generator, IEEE Transactions on Industrial Electronics, vol.56, no.10, (2009),pp: 4220-4228

[8] Xiong Fei, Research on Modeling Analysis and Electromagnetic Design of Wound-Rotor Brushless Doubly-Fed Machine , $\mathrm{PhD}$ thesis, Wuhan, Huazhong University of Science and Technology, ( 2010)

[9] XIE Di, LU Zhanhui, LI Gengyin, LIU Zhongyi, Interval Stability Analysis of Small Signal for a Class of Power System With Asynchronous Wind Turbine Generators, Proceeding of the CSEE, vol.35, no.3, ( 2015), pp: 609-614

[10] Li Yang, The Study of the Influence of the Large-scale Integration of Wind Power Generation on the Small Disturbance Stability of Power System, Mater thesis, Beijing, North China Electric Power University, (2013) 